\title{
Properties of the Optical Planar Polymer Waveguides Deposited on Printed Circuit Boards
}

\author{
Vaclav PRAJZLER ${ }^{1}$, Pavla NEKVINDOVA ${ }^{2}$, Petr HYPS ${ }^{1}$, Vitezslav JERABEK ${ }^{1}$ \\ ${ }^{1}$ Dept. of Microelectronics, Czech Technical University, Technická 2, 16827 Prague, Czech Republic \\ ${ }^{2}$ Institute of Chemical Technology, Technická 5, 16627 Prague, Czech Republic
}

xprajzlv@feld.cvut.cz

\begin{abstract}
This paper reports on a technology for realization of an optical planar waveguide layer on duroid substrate and on FR4 fiber reinforced board material printed circuit boards. Waveguide core material was EpoCore polymer and for claddings we used EpoClad polymer. Design of the presented planar waveguides was realized on the bases of modified dispersion equation and was schemed for $633 \mathrm{~nm}, 964 \mathrm{~nm}, 1310 \mathrm{~nm}$ and $1550 \mathrm{~nm}$ wavelength. Waveguiding properties were measured by dark mode spectroscopy while propagation optical loss measurement was done by the fiber probe technique at wavelegnth $633 \mathrm{~nm}$ (He-Ne laser). The samples had optical losses lower than $0.5 \mathrm{~dB} / \mathrm{cm}$. The best sample has optical losses around $0.25 \mathrm{~dB} / \mathrm{cm}$.
\end{abstract}

\section{Keywords}

Optical polymer waveguide, planar waveguides, printed circuit boards

\section{Introduction}

In recent years high-performance electronic systems have highlighted the importance of developing new interconnection technologies to overcome the inherent disadvantages of copper interconnection technologies when operating at high data rates [1-3]. It is due to the continuous demand over the past several decades for increasingly high performance computers with more complex and integrated systems that has pushed traditional electronic interconnect links to their functional limits [4], [5]. Existing interconnection technologies have been using mainly metal copper wiring connection, however, rising data-rates and their sensitivity to electromagnetic interference will soon make them unable to keep up [6] due to several drawbacks of copper wire tracks such as lower bandwidth, higher susceptibility to crosstalks and electromagnetic interference. These drawbacks can be overcome by using optical interconnections, which possess several advantages, such as immunity to the electromagnetic interference, independency to impedance mismatch, less power consumption, and high-speed operation. Nevertheless, besides the mentioned advantages compared with the copper interconnection, optical interconnection systems still suffer from some problems concerning packaging, multilayer technology, signal tapping, and rework ability.

Traditional photonics planar structures and devices have been made of semiconductors, inorganic crystals and glasses. Due to easy integration process with other optical and electrical elements, it would be convenient to realize the optical waveguides on silicon substrate [7]. Though integration of optical waveguides and opto-electronic components for on-board optical communications have already been developed using flexible foils substrates [3], [4], in the case of the optical interconnection it is highly desirable to realize optical waveguides also on printed circuit boards. For this purpose most often used substrates are "fiber reinforced board material electrical circuit boards" called FR-4; and for high frequency board are commonly used RT/Duroid high frequency polytetrafluorethylen (PTFE) composites reinforced with glass microfibers [8]. FR-4 is the primary insulating backbone upon which the vast majority of rigid printed circuit boards (PCBs) are produced. In such type of the device a thin layer of copper foil is one or both sides laminated with FR-4 glass epoxy panel. The FR-4 material is known to retain its high mechanical values and electrical insulating qualities in both dry and humid conditions [9]. These attributes, together with good fabrication characteristics, lend utility to this grade for a wide variety of electrical and mechanical applications. RT/Duroid microfiber reinforced PTFE composites were designed for exacting stripline and microstrip circuit applications such as airborne and ground based radar systems, millimeter wave applications, point to point digital radio antennas and space satellite transceivers. For such applications RT/Duroid has sufficiently low electrical losses, low moisture absorption, uniform electrical properties over frequency, excellent chemical resistance as well as low outgassing for space applications etc. [8].

As mentioned above, such substrates are of a great potential for realizing new photonics and high frequency applications. Therefore, for our research, we choose EpoCore polymer as a core waveguide material and for claddings we used EpoClad polymer; both supported by Micro resist technology $\mathrm{GmbH}$. Last but not least, such polymers possess excellent properties such as high heat and pressure resistance, low optical losses $\left(0.2 \mathrm{~dB} \cdot \mathrm{cm}^{-1}\right.$ at $850 \mathrm{~nm}$, re- 
fractive index $\lambda=830 \mathrm{~nm}$ : EpoCore 1.58, EpoClad 1.57) [10], easy fabrication process, etc. For a substrate we used RT/Duroid 5880 laminates and flexible FR-4 composite material with thickness of $100 \mu \mathrm{m}$.

\section{Design of the Planar Wave- guides}

Planar optical waveguide is a slab dielectric material surrounded by media with lower refractive indices. The light is guided inside the slab by total internal reflection. Thin film slab planar optical waveguide consisting of core, upper and lower layers called cover and cladding, respectively, is illustrated in Fig. 1.

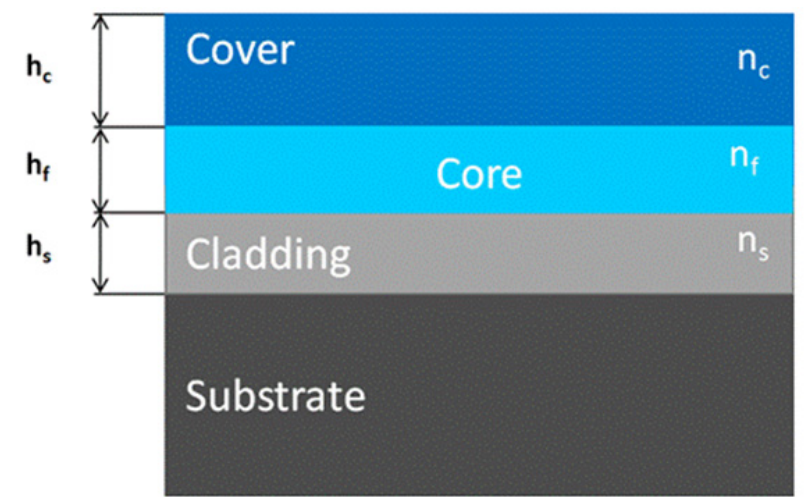

Fig. 1. Scheme of an optical planar waveguide.

Now we are going to design optical planar waveguides with RT/Duroid and FR-4 laminate substrates, EpoClad cladding layer, EpoCore polymer waveguide; the upper side will be left open so that the air will act as a "cover" $\left(n_{\mathrm{c}}\right)$. Number of guided modes $(m)$ and thickness $\left(h_{f}\right)$ of the core of the optical waveguide can be determined by solving of modified dispersion equation [11], [12]:

$$
\begin{gathered}
m=\operatorname{INT}\left\{\frac{2}{\lambda_{0}} h_{f} \sqrt{n_{f}^{2}-n_{c}^{2}}-\frac{1}{\pi} \operatorname{arctg}\left[p \sqrt{\frac{n_{s}^{2}-n_{c}^{2}}{n_{f}^{2}-n_{s}^{2}}}\right]\right\}, \\
h_{f}=\frac{\lambda_{0}}{2 \pi \sqrt{n_{f}^{2}-n_{s}^{2}}}\left\{n \pi+\operatorname{arctg}\left[p \sqrt{\frac{n_{s}^{2}-n_{c}^{2}}{n_{f}^{2}-n_{s}^{2}}}\right]\right\}
\end{gathered}
$$

where $\lambda_{0}$ is operating wavelength, $n$ is an integer number $n=0,1,2 \ldots$, and $p$ is for the TE mode

$$
p=1
$$

and for the TM mode

$$
p=\left(\frac{n_{f}}{n_{s}}\right)^{2} .
$$

The actual proposal of the optical planar waveguide was done by using the tabular value of the refractive indices for applied materials (see Fig. 2) [10].

Before realizing the design we checked the properties of the used polymers. For that, the polymer layers were

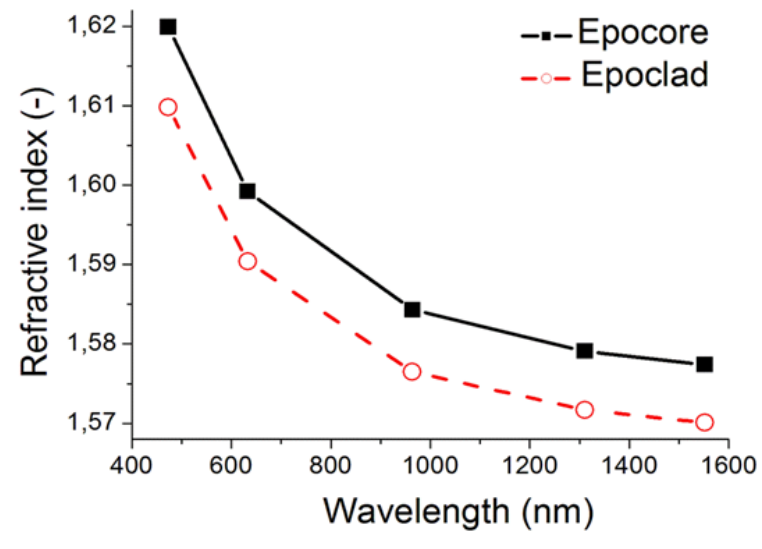

Fig. 2. Tabular value of the refractive indices of EpoCore waveguide layer and EpoClad cladding layer [10].

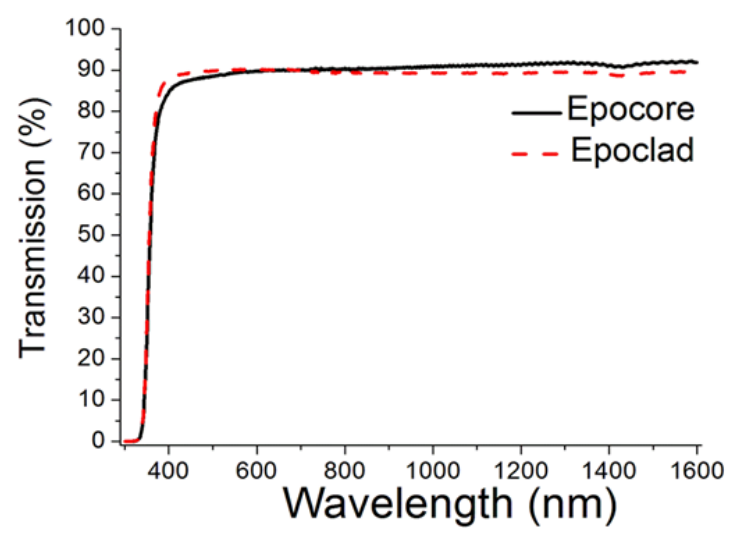

Fig. 3. Transmission spectra of EpoCore waveguide layer and EpoClad cladding layers.

\begin{tabular}{|c|c|c|}
\hline \multirow{2}{*}{$\begin{array}{c}\text { Wavelength } \\
(\mathrm{nm})\end{array}$} & \multicolumn{2}{|c|}{ Refractive index (-) } \\
\cline { 2 - 3 } & EpoClad & EpoCore \\
\hline 473 & 1.610 & 1.620 \\
\hline 633 & 1.590 & 1.599 \\
\hline 850 & 1.581 & 1.589 \\
\hline 964 & 1.577 & 1.584 \\
\hline 1310 & 1.572 & 1.579 \\
\hline 1550 & 1.570 & 1.577 \\
\hline
\end{tabular}

Tab. 1. Refractive indices used for design of the EpoClad cladding and EpoCore waveguide layer [10].

deposited onto glass substrates and transmission spectra of the used cladding and core waveguide layers were collected by UV-VIS-NIR Spectrometer (UV-3600 Shimadzu) in the spectral range from 300 to $1600 \mathrm{~nm}$. The results are given in Fig. 3. Obviously the waveguide layers are transparent almost within the range from $400 \mathrm{~nm}$ to $1600 \mathrm{~nm}$.

Refractive indices for the EpoClad cladding and EpoCore core waveguides layers used for the design of the planar waveguides are listed in Tab. 1.

As the design was intended for standard 50/125 $\mu \mathrm{m}$ fibers, it was convenient to work with $50 \mu \mathrm{m}$ thick planar waveguide layer. The results of mode calculations performed for wavelength of $633 \mathrm{~nm}, 964 \mathrm{~nm}$ and $1311 \mathrm{~nm}$ for TE modes (for the thickness of the waveguiding layer $50 \mu \mathrm{m})$ are shown in Fig. 4. The calculations showed that the waveguides supported 27 modes at $633 \mathrm{~nm}, 15$ modes at $964 \mathrm{~nm}$ and 11 modes at $1310 \mathrm{~nm}$. 


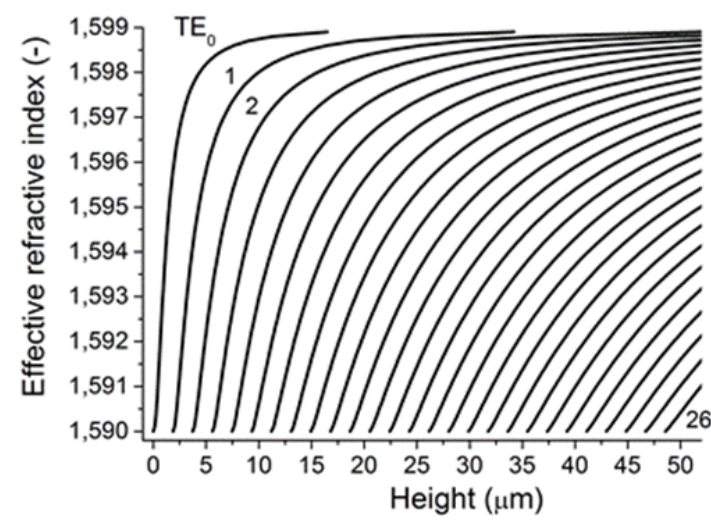

a)

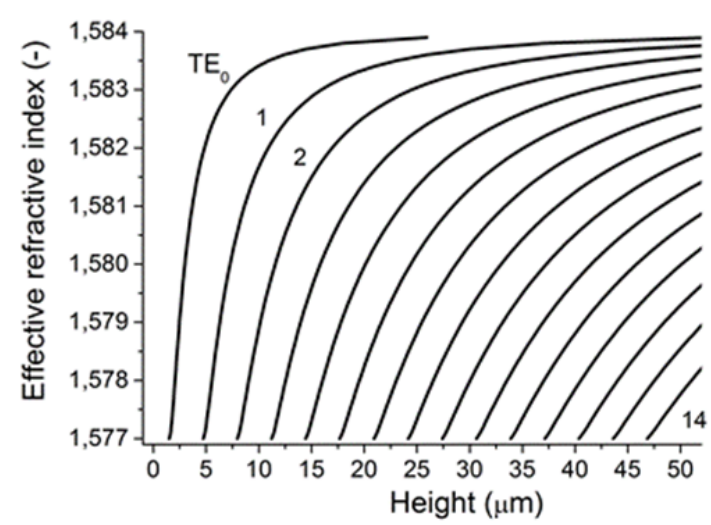

b)

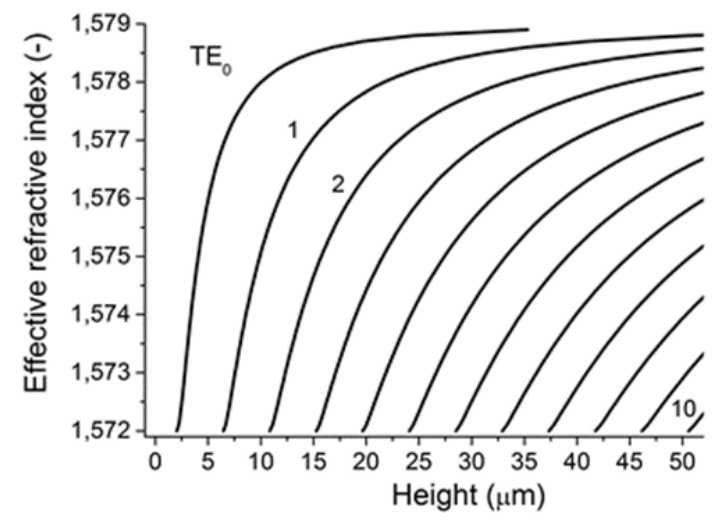

c)

Fig. 4. TE mode calculation of the polymer planar waveguides for thickness of the waveguide layer $50 \mu \mathrm{m}$ and for wavelength a) $633 \mathrm{~nm}$, b) $964 \mathrm{~nm}$ and c) $1311 \mathrm{~nm}$.

\section{Fabrication of the Waveguides}

The experiments were performed on RT/Duroid 5880 (supported by Rogers Corporation) and FR-4 without copper layer (supported by PRINTED s.r.o.) substrates. Cladding was made of EpoClad polymer and the core of the waveguide was negative tone photoresists EpoCore polymer (supplied by Micro resist technology GmbH). Fabrication process of the optical planar waveguides is step by step illustrated in Fig. 5.

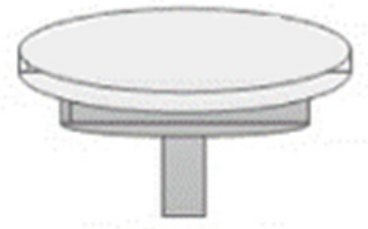

a)

\section{Epoclad}

b)

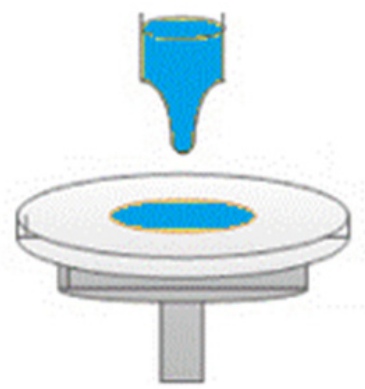

Epocore

c)

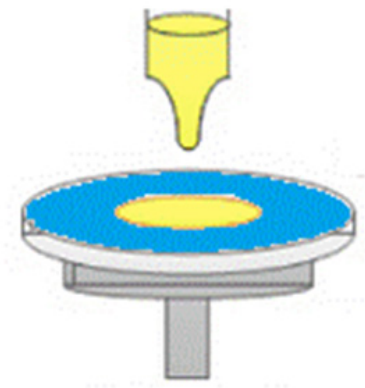

UV Light

d)
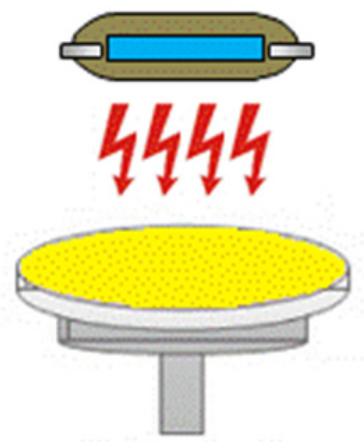

Fig. 5. Fabrication process for EpoCore optical planar waveguides: a) substrate cleaning, b) deposition of EpoClad cladding layer, c) deposition of EpoCore waveguide layer and d) UV curing process.

The first step was a standard cleaning procedure followed by deposition of primer (MCC Primer 80/20 - MicroChem P021020) to improve adhesion (Fig. 5a). Then EpoClad cladding layers were deposited on the substrate by spin coating (Fig. 5b) and after that soft bake process was applied at $50^{\circ} \mathrm{C}$ for $10 \mathrm{~min}$ on a hotplate. Then the temperature was gradually increased to $80^{\circ} \mathrm{C}\left(10^{\circ} \mathrm{C} / \mathrm{min}\right)$. The next step was deposition of EpoCore layer on it by spin coating (Fig. 5c) and again, soft bake process was applied at $50^{\circ} \mathrm{C}$ for $10 \mathrm{~min}$ on the hotplate. Then the temperature was once again gradually increased to $80^{\circ} \mathrm{C}\left(10^{\circ} \mathrm{C} / \mathrm{min}\right)$. 
Next, applying of UV curing process (Fig. 5d) occurred and, finally, post exposure bake was done at $50^{\circ} \mathrm{C}$ for 10 min on hotplate. The last step was to increase gradually temperature $\left(10^{\circ} \mathrm{C} / \mathrm{min}\right)$ again to $80^{\circ} \mathrm{C}$.

\section{Results}

The thicknesses of the fabricated polymer layers were measured by profile-meters Talystep Hommel Tester 1000 . The experimentally found thicknesses of the cladding and core waveguide layers were around $50 \mu \mathrm{m}$ depending on the rate of spinning of the coater during the deposition.

The fabricated samples are shown in Fig. 6. The EpoCore waveguide on RT/Duroid substrate is given in Fig. $6 \mathrm{a}$ and the fabricated polymer planar waveguide on FR-4 substrate is in Fig. 6b. The figures reveal that the waveguides had good optical quality with minimum defects.
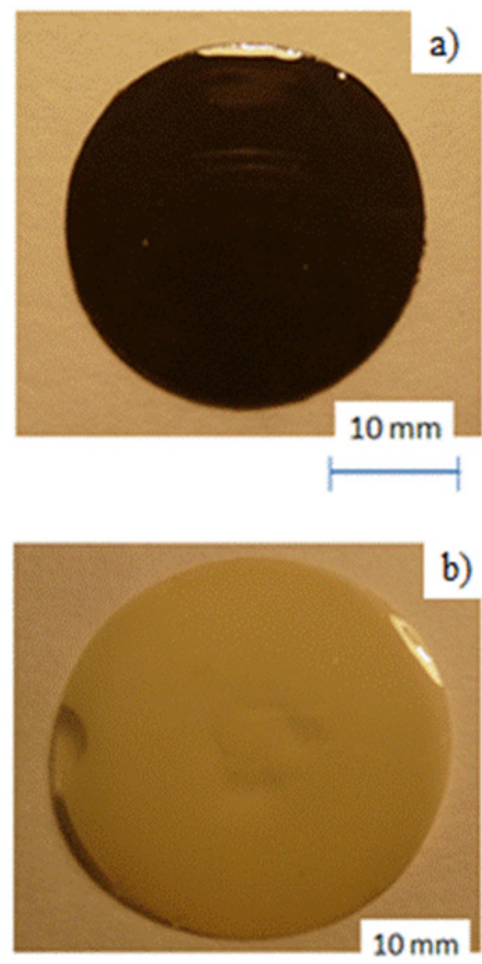

Fig. 6. Images of the EpoCore polymer waveguides fabricated on a) RT/Duroid and b) FR-4 substrate.

Waveguiding properties of the EpoCore planar waveguides were examined by dark mode spectroscopy using Metricon 2010 prism-coupler system at five wavelengths 473, 633, 964, 1311 and $1552 \mathrm{~nm}$ (principle of this measurement has been already described in [13-15]) and the results in the form of mode spectra are given in Fig. 7 for planar EpoCore waveguides on RT/Duroid substrate and in Fig. 8 for the waveguide on FR-4 substrate.
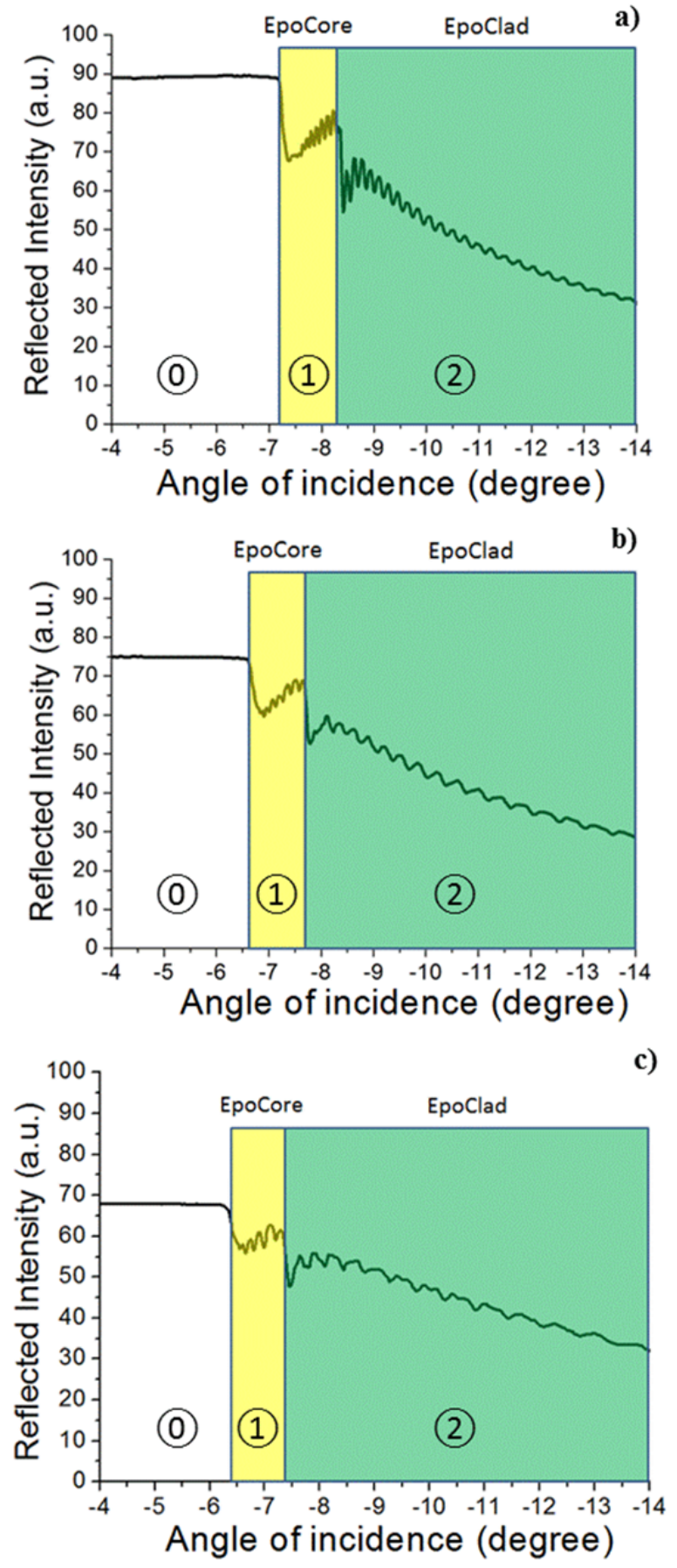

Fig. 7. Mode pattern of EpoCore/EpoClad planar waveguides on RT/Duroid substrate (TE modes) for wavelength: a) $633 \mathrm{~nm}$, b) $964 \mathrm{~nm}$, c) $1311 \mathrm{~nm}$.

Area (0) corresponds to air cover layer. Area (1) corresponds to EpoCore waveguide layer and, according to the calculations, it might show 27 modes at $633 \mathrm{~nm}$ (Fig. 7a and Fig. 8a), 15 modes at $964 \mathrm{~nm}$ (Fig. 7b and Fig. 8b) and 11 modes at $1311 \mathrm{~nm}$ (Fig. 7c and Fig. 8c). However, the area is too narrow to have all these modes clearly pronounced so that they blend each with other. Area (2) represents EpoClad cladding layer. 

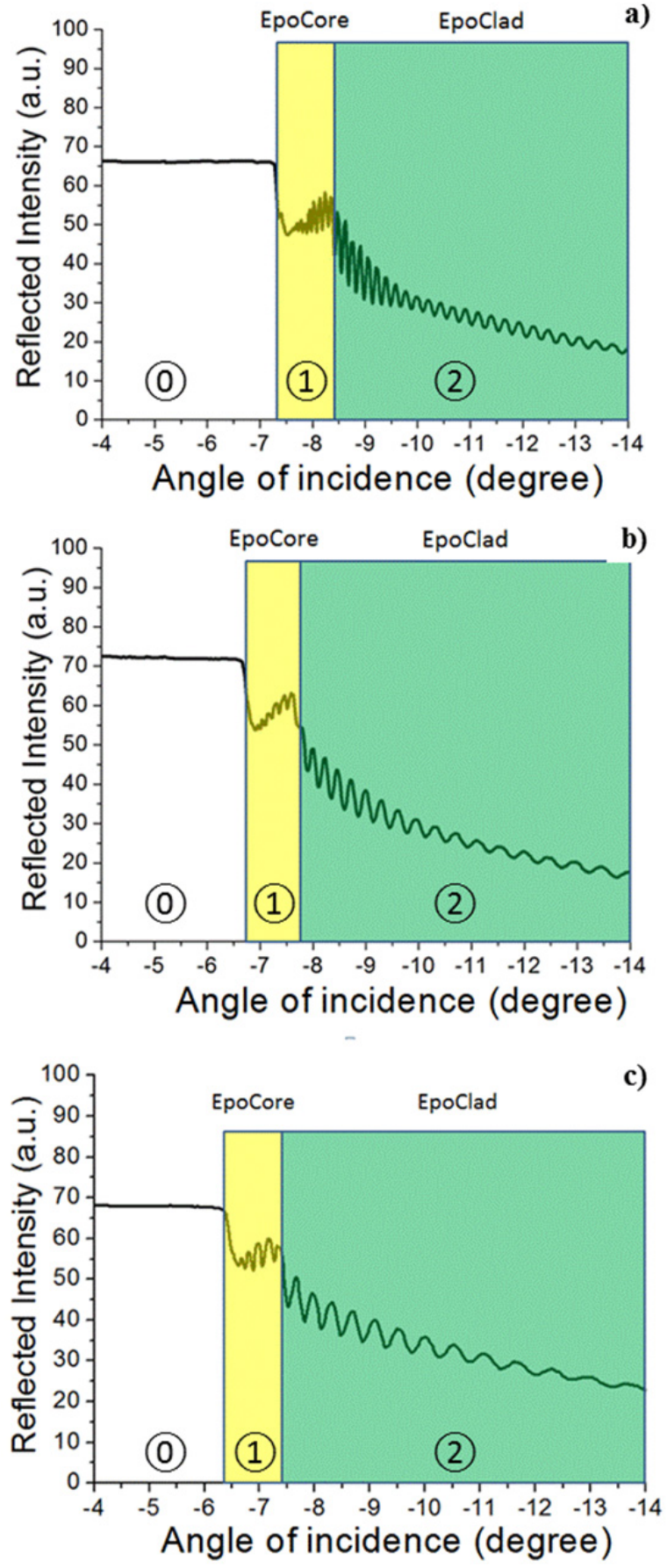

Fig. 8. Mode pattern of EpoCore/EpoClad planar waveguides on FR-4 substrate (TE modes) for wavelength: a) $633 \mathrm{~nm}$, b) $964 \mathrm{~nm}$ and c) $1311 \mathrm{~nm}$.

From incident angle $\theta_{\mathrm{c}}$ value one can determine the refractive index value of the core and cladding layer substituting them to (5) [13]:

$$
\theta_{c}=\arcsin \left(\frac{n}{n_{p}}\right)
$$

where $n_{p}$ is the refractive index of the used coupling prism and $n$ is then the value of the refractive index of the core or the cladding layer respectively. Here we used the surface incident angle value and core layer incident angle value from the interface between (0) and (1) to get the pertinent refractive index values for EpoCore waveguide layer. The surface incident angle value between (1) and (2) give us refractive index for EpoClad layer. The obtained values of refractive indices are given in Tab. 2.

\begin{tabular}{|c|c|c|c|c|}
\hline \multirow{2}{*}{$\begin{array}{c}\text { Wavelength } \\
(\mathrm{nm})\end{array}$} & \multicolumn{3}{|c|}{ Refractive index (-) } \\
\cline { 2 - 5 } & \multicolumn{2}{|c|}{ RT/Duroid } & \multicolumn{2}{c|}{ FR-4 } \\
\cline { 2 - 5 } & EpoClad & EpoCore & EpoClad & EpoCore \\
\hline 473 & 1.597 & 1.615 & 1.594 & 1.613 \\
\hline 633 & 1.579 & 1.594 & 1.578 & 1.593 \\
\hline 964 & 1.567 & 1.580 & 1.567 & 1.580 \\
\hline 1311 & 1.562 & 1.575 & 1.562 & 1.574 \\
\hline 1552 & 1.561 & 1.573 & 1.559 & 1.573 \\
\hline
\end{tabular}

Tab. 2. Evaluation of the refractive indices for the EpoClad cladding and EpoCore waveguide layer by using dark mode spectroscopy.

Optical losses of the planar waveguides were measured by technique that involves measurement of transmitted and scattered light intensity as a function of propagation distance along the waveguide [12], [16] The light was coupled into the planar waveguides through optical coupling prism and the outgoing scattered light intensity was detected by optical fiber connected to Si detector. Fig. 9 shows an image of planar waveguides supporting light at $633 \mathrm{~nm}$ where Fig. 9a shows propagation of the light through EpoCore planar waveguides on RT/Duroid substrate while propagation of the light through EpoCore planar waveguides on FR-4 substrate is given in Fig. 9b. Because in this case the substrate is very thin $(100 \mu \mathrm{m})$ we have to underlay it with a pad of glass to achieve optical contact.

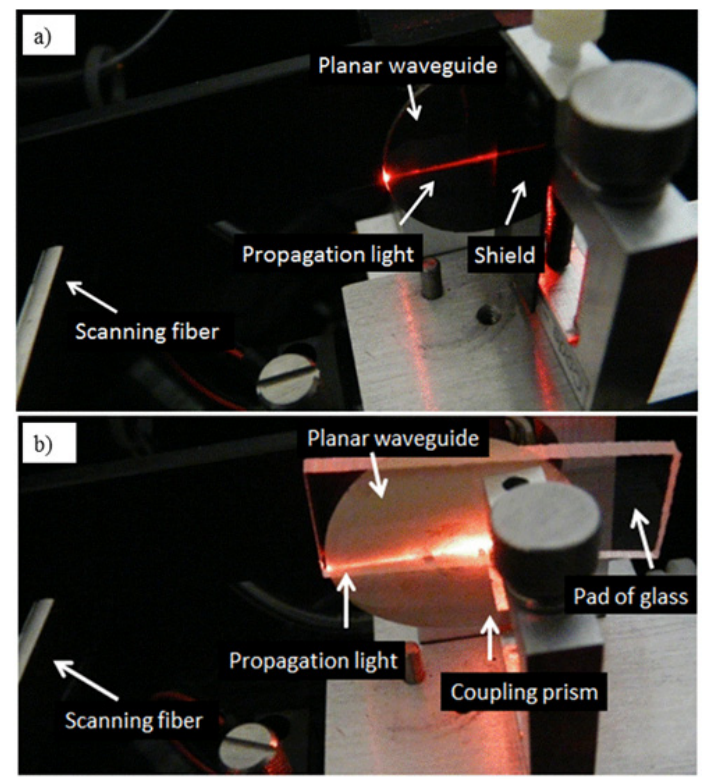

Fig. 9. Coupling of the optical light $(633 \mathrm{~nm})$ into the planar EpoCore waveguides for optical loss measurements on a) RT/Duroid substrate and b) FR-4 substrate.

Optical loss measurements are demonstrated in Fig. 10 showing results for planar waveguide EpoCore/Duroid in Fig. 10a and the results for EpoCore/FR-4 waveguide in Fig. 10b. The values of optical losses were determined for the stabilized optical field that occurred within 2 to $5 \mathrm{~cm}$ for waveguide on RT/Duroid substrate and 3 to 


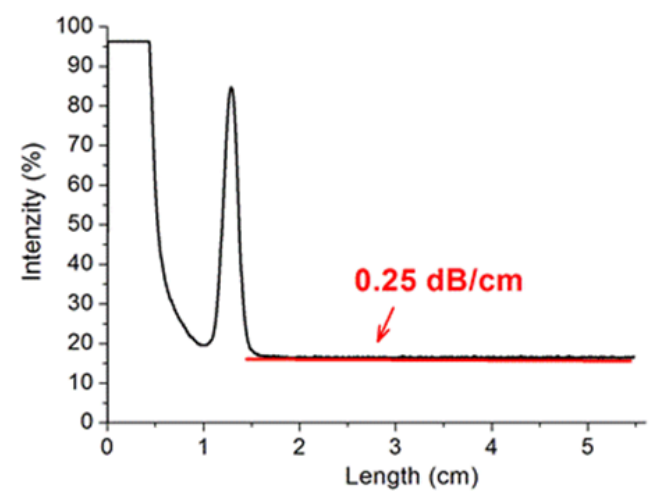

a)

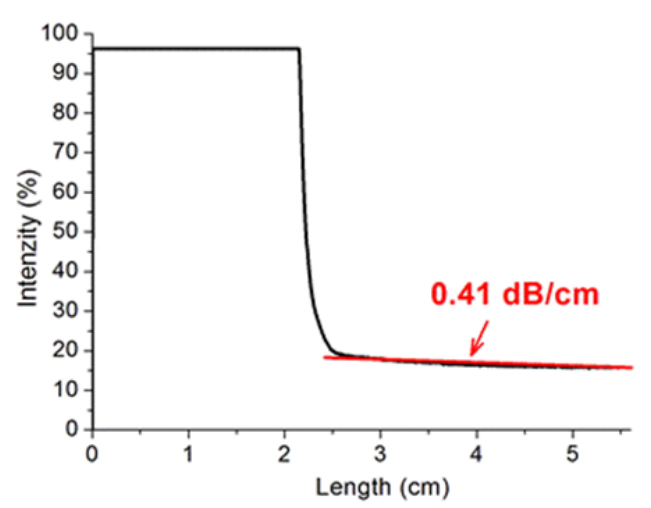

b)

Fig. 10. Optical losses of the EpoCore waveguides for wavelength $633 \mathrm{~nm}$ on a) RT/Duroid and b) FR-4 substrate.

$5 \mathrm{~cm}$ for waveguide on FR-4 substrate. Our optical planar waveguides had optical losses lower than $0.5 \mathrm{~dB} / \mathrm{cm}$ with the best sample having optical losses as low as $0.25 \mathrm{~dB} / \mathrm{cm}$.

\section{Conclusion}

We report about properties of EpoCore polymer planar waveguides fabricated on RT/Duroid and flexible FR4 substrate. Planar waveguides were deposited by spin coating after that UV curing was applied for hardening of the deposited waveguide layers.

Optical waveguiding properties of our planar waveguide samples were characterized by Metricon 2010 prismcoupler system for five wavelengths $(473,633,964,1311$ and $1552 \mathrm{~nm}$ ) and optical losses were measured by collecting the scattered light using fiber scanning along the waveguide read by the Si photodetector at $633 \mathrm{~nm}$. The samples had optical losses less than $0.5 \mathrm{~dB} / \mathrm{cm}$ and the best sample had optical losses around $0.25 \mathrm{~dB} / \mathrm{cm}$.

The main advantage of our waveguides is that in the case of FR-4 substrate they allow for realization of optoelectronic devices for purely optical interconnection. Another main advantage is that they are made on RT/Duroid microfiber reinforced polytetrafluorethylen substrate, i.e., the material that is suitable for realization of optoelectronics devices for high frequency applications. Our next goal is to design and construct multimode ridge waveguides based on the same principle.

\section{Acknowledgments}

Our research is supported by the Epsilon Programme of the Technology Agency of the Czech Republic, project no. TH01020276, and by the CTU grant no. SGS14/195/OHK3/3T/13.

\section{References}

[1] BAMIEDAKIS., N., HASHIM, A., PENTY, R. V., WHITE, I. H. A $40 \mathrm{~Gb} / \mathrm{s}$ optical bus for optical backplane interconnections. IEEE Journal of Quantum Electronics, 2009, vol. 32, no. 8, p. 1526-1537. DOI: $10.1109 / J L T .2014 .2306983$

[2] SWATOWSKI, B. W., AMB, C. M., BREED, S. K., DESHAZER, D. J., WEIDNER, W. K., DANGEL, R.F., MEIER, N., OFFREIN, B. J. Flexible, stable, and easily processable optical silicones for low loss polymer waveguides. In Proceedings of SPIE, vol. 8622, 2013. DOI: $10.1117 / 12.2007419$

[3] CHOI, C., LIN, L., LIU, Y., CHOI, J., WANG, L., HAAS, D., MAGERA, J., CHEN, R.T. Flexible optical waveguide film fabrications and optoelectronic devices integration for fully embedded board-level optical interconnects. Journal of Lightwave Technology, 2004, vol. 22, no. 9, p. 2168-2176. DOI: 10.1109/JLT.2004.833815

[4] BOSMAN, E., Van STEENBERGE, G., Van HOE, B., Van MISSINNE, J., Van FETEREN, J., Van DAELE, P. Highly reliable flexible active optical links. IEEE Photonics Technology Letters, 2010, vol. 22, no. 5, p. 287-289. DOI: 10.1109/LPT.2009.2038797

[5] DANGEL, R., HORST, F., JUBIN, D., MEIER, N., WEISS, J., OFFREIN, B. J., SWATOWSKI, B. W., AMB, C. M., De SHAZER, D. J., WEIDNER, W. K. Development of versatile polymer waveguide flex technology for use in optical interconnects. Journal of Lightwave Technology, 2013, vol. 31, no. 24, p. 3915-3926. DOI: 10.1109/JLT.2013.2282499

[6] ISHIDA, Y., HOSOKAWA, H. Optical link utilizing polymer optical waveguides application in multimedia device. In Proceedings SPIE,. Photonics in Multimedia II, 2008, vol. 7001, p. 70010J-1 - 70010J-9. DOI: 10.1117/12.780166

[7] PRAJZLER, V., KLAPUCH, J., LYUTAKOV, O., HÜTTEL, I., ŠPIRKOVÁ, J., NEKVINDOVÁ, P., JEŘÁBEK, V. Design, fabrication and properties of rib poly (methylmethacrylimide) optical waveguides. Radioengineering, 2011, vol. 20, p. 479-485.

[8] Rogers corporation: Advanced Circuit Materials Division Data Sheet RT/duroid ${ }^{\circledR} 5870 / 5880$ Laminates. [Online] Available at: www.rogerscorp.com

[9] PCB Fabrication Material. [Online] Available at: http://www.pcbfabrication.com/

[10] Micro Resist Technology GmbH, datasheet. [Online] Available at: http://www.microresist.de

[11] POLLOCK, C., LIPSON, M. Integrated Photonics. Kluwer Academic Publishers, 2003. ISBN: 1402076355

[12] PRAJZLER, V., NEKVINDOVÁ, P., HYPŠ, P., LYUTAKOV, O., JERABEK V. Flexible polymer planar optical waveguides, Radioengineering, 2014, vol. 23, no. 3, p. 776-782.

[13] web Metricon Corporation Available at: www.metricon.com

[14] ULRICH, R., TORGE, R. Measurement of thin film parameters with a prism coupler. Applied Optics, 1973, vol. 12, no. 12, p. 2901-2908. DOI: 10.1364/AO.12.002901

[15] PRAJZLER, V., VARGA, M., NEKVINDOVÁ, P., REMEŠ, Z., KROMKA, A. Design and investigation of properties of nanocrystalline diamond optical planar waveguides. Optics 
Express, 2013, vol. 21, no. 7, p. 8417-8425. DOI: 10.1364/OE.21.008417

[16] NOURSHARGH, N., STARR, E. M., FOX, N. I., JONES, S. G. Simple technique for measuring attenuation of integrated optical waveguides. Electronics Letters, 1985, vol. 21, no. 18, p. 818-820. DOI: $10.1049 / \mathrm{el}: 19850577$

\section{About the Authors ...}

Václav PRAJZLER was born in 1976 in Prague, Czech Republic. In 2001 he graduated from the Faculty of Electrical Engineering, Czech Technical University in Prague, Dept. of Microelectronics. Since 2005 he has been working at the same department as a research fellow. In 2007 he obtained the $\mathrm{PhD}$ degree from the same university. His current research is focused on design, fabrication and investigation properties photonics structures.

Pavla NEKVINDOVÁ was born in 1972 in Kolín, Czech Republic. She graduated from the Institute of Chemical
Technology, Prague (ICTP) in 1999. Now she is the Assistant Professor at the ICTP giving lectures on general and inorganic chemistry. She has worked there continuously in materials chemistry research. She has a long-term experience with fabrication and characterization of optical waveguiding structures in single-crystalline and glass materials.

Petr HYPŠ was born in 1989 in Pelhřimov, Czech Republic. He has studied at the Faculty of Electrical Engineering, Czech Technical University in Prague. In June 2013 he obtained the bachelor's degree in Communication, Multimedia and Electronics. Now his field of study is polymer photonics structures.

Vítězslav JEŘÁBEK was born in Prague in 1951. He received his M.Sc. and Ph.D. in the Microelectronics from the Czech Technical University in Prague in 1975 and 1987. He is currently an Associate Professor of Electronics and head of Optoelectronic group at the Microelectronic Department, Czech Technical University in Prague. 